\title{
PREPARATION OF WATER-SOLUBLE DIALDEHYDE NANOCELLULOSES BY PERIODATE OXIDATION UNDER MICROWAVE IRRADIATION
}

\author{
CHEOL-WOONG YANG and HYUNG-MIN CHOI \\ Department of Organic Materials and Fiber Engineering, Soongsil University, Seoul, \\ Republic of Korea 06978 \\ Corresponding author: Hyung-Min Choi, hchoi@ssu.ac.kr
}

Received November 21, 2019

\begin{abstract}
Water-soluble dialdehyde nanocellulose was readily produced at room temperature by sodium periodate oxidation under microwave irradiation. The effect of various experimental parameters, such as reaction temperature, cellulose to periodate ratio and microwave power, on periodate oxidation of cellulose, during one to five hours of irradiation, were investigated. FT-IR spectroscopy and aldehyde content analyses revealed two stage reaction rates: an initial rapid oxidation in the amorphous region, followed by a slower second reaction across the crystalline surface. The chaincleavage accompanying the introduction of dialdehyde groups contributed to an increase in the water solubility and a decrease in the thermal stability of cellulose nanoparticles, which reached sizes of about 200-300 $\mathrm{nm}$. The five specimens prepared using three to five hours of microwave irradiation were readily dissolved in water by simple stirring at room temperature. Additional heating at $55^{\circ} \mathrm{C}$ for an hour solubilized the other specimens. XRD investigation substantiated a decrease in the crystalline area by ring breakage. FeSEM analyses also verified the morphological changes that occurred in the oxidized nanocelluloses.
\end{abstract}

Keywords: nanocellulose, sodium periodate oxidation, microwave irradiation, dialdehyde, water solubility

\section{INTRODUCTION}

Cellulose is the most abundant natural polymer on the earth and is potentially a material with wide applicability in various fields due to its lightness, strong mechanical properties, biodegradability and biocompatibility. ${ }^{1}$ The enduses of cellulose in the non-textile area are diverse: from fillers in nanocomposites, to scaffolds in drug delivery, in food packaging and in many other areas. In these applications, cellulose molecules are generally prepared in nano-size, with uniform particles and diverse functional groups, the applications often requiring water solubility. ${ }^{2-15}$

The processing of cellulose to nano-size to satisfy these characteristics can be performed by physical and chemical methods. ${ }^{5}$ Physical methods by using high-shear homogenization and ball milling have the disadvantages of requiring high energy and long processing time. In addition, it is often difficult to produce uniform particles and introduce the functional groups needed. This hinders commercial-scale production of nanocellulose by such methods. ${ }^{5,6}$ In the case of chemical methods, these involve the use of (2,2,6,6-tetrametylpiperidin-1-yl)oxyl, commonly known as TEMPO and sodium periodate (SP) oxidation; the oxidation of hydroxyl groups weakens intra- and inter-hydrogen bonds inside of the cellulose chain and causes the decomposition of the amorphous material. ${ }^{7}$ This enables the production of crystalline nanocellulose. TEMPO reaction induces carboxyl groups through oxidation of hydroxyl groups at C6 carbon. ${ }^{2}$ On the other hand, SP oxidation breaks the bond of C2-C3 carbons in the glucose ring, introducing dialdehyde groups into these positions. ${ }^{2,4}$ SP oxidation is thus preferred over TEMPO oxidation because these aldehyde groups can be readily modified into various other functional groups. ${ }^{4,7-11}$ Cellulose materials with reactive functional groups could be used in various applications, such as adsorbents for heavy metal, protein, or 
dye. ${ }^{8,11,12}$ In addition, SP oxidized cellulose is biodegradable and biocompatible. ${ }^{13,14}$

However, one notable disadvantage of SP oxidized cellulose is its insolubility in water and other common organic solvents, even after complete oxidation. ${ }^{4}$ It is known that SP oxidized cellulose is only soluble in water after conversion of its aldehyde groups into primary alcohols, carboxylic acid, or imine. ${ }^{4,11}$ This insolubility has been attributed to hemiacetal formation of aldehyde groups with the remaining hydroxyl groups of cellulose. ${ }^{4,8}$ It has been also found that the fully SP oxidized cellulose can be dissolved in water at high temperature, such as $80{ }^{\circ} \mathrm{C}$ and 100 ${ }^{\circ} \mathrm{C}$, for one to six hours of heating. ${ }^{4}$

SP oxidation of cellulose in water also requires a very long reaction time to achieve high aldehyde contents, because of the low reactivity of cellulose. ${ }^{8,14}$ It often needs more than 10 days of reaction time at room temperature in a dark environment. ${ }^{4,8,17}$ This reduces the effectiveness of oxidation, leading to large amounts of iodinecontaining waste. ${ }^{14}$ Several studies examined ways to shorten the reaction time for SP oxidation. $^{10,11,14}$ The use of sulfuric acid pretreatment reduced the reaction time to four hours, but it required a strong acid. ${ }^{10}$ SP oxidation was significantly enhanced and the reaction time was shortened to one to three hours at $55^{\circ} \mathrm{C}$ to 85 ${ }^{\circ} \mathrm{C}$ in the presence of metal salts, such as lithium chloride, as cellulose activator. ${ }^{14}$

In conventional heating, an external high heat energy is transferred to the inside, whereas microwave generates energy efficiently by transferring heat energy directly to the inside of the sample evenly and rapidly. ${ }^{18,19}$ SP particles can move forward and backward through ionic conduction by the microwave field and generate heat, due to collisions, producing local high instantaneous heat and increase reactivity during microwave irradiation. ${ }^{19}$ In a previous study, we have already shown that microwave irradiation could be adequately used in SP oxidation of cellulose. ${ }^{11}$ Using the advantages of heating by microwave radiation, this study overcomes the problems of requiring long reaction time and use of high thermal energy for the preparation of water-soluble cellulose nanoparticles. The purpose of this study is therefore to investigate the effects of changes in microwave irradiation conditions on the preparation of water-soluble dialdehyde cellulose and, finally, to characterize the produced cellulose nanoparticles.

\section{EXPERIMENTAL \\ Materials}

Cellulose powder (C6288), diethylene glycol and methyl orange were purchased from Sigma-Aldrich Co. Ltd., Korea. Sodium periodate $\left(\mathrm{NaIO}_{4}, 99.5 \%\right.$, SP) was received from Wako Pure Chemical Industries Ltd., lithium chloride (LiCl, 98\%) was obtained from YAKURI Pure Chemical Co. Ltd., hydroxylamine hydrochloride and sodium hydroxide $(\mathrm{NaOH})$ were purchased from Samjeon Pure Chemical Co., Ltd. (Korea). These chemicals were all reagent grade and used without purification.

\section{Preparation of dialdehyde cellulose (DAC)}

Three concentrations of SP (6 g, 9 g, 12 g) and 2.7 $\mathrm{g}$ of $\mathrm{LiCl}$ were added to $300 \mathrm{~mL}$ of distilled water in a $500 \mathrm{~mL}$ Erlenmeyer flask, and then dissolved for 10 minutes with stirring. Three grams of cellulose powder was added to the flask, covering completely by a Teflon film to protect from light. The flask containing the reagent and cellulose was heated at three temperatures $\left(35{ }^{\circ} \mathrm{C}, \quad 55{ }^{\circ} \mathrm{C}, \quad 75{ }^{\circ} \mathrm{C}\right)$ and three microwave power levels $(400 \mathrm{~W}, 700 \mathrm{~W}, 1000 \mathrm{~W})$ for one to five hours at one hour interval. A microwave synthesis extraction reactor (Uwave-2000, Sieno Microwave Chemistry Technology Co., Ltd., China) was used to irradiate the specimens. Three reaction parameters were varied: cellulose and SP ratio (w/w), microwave radiation power and reaction temperature, consequently, thirty-five specimens were prepared, as listed in Table 1. After the reaction was completed, an amount of $11.5 \mathrm{~mL}, 17.25 \mathrm{~mL}$ or $23 \mathrm{~mL}$ of diethylene glycol was added to the baths containing $6 \mathrm{~g}, 9 \mathrm{~g}$ or 12 $\mathrm{g}$ of SP, respectively, to terminate the oxidation reaction. The specimens produced were washed three times with deionized water by using a membrane tube to remove residual reagents, and solid DAC nanoparticles were finally obtained after lyophilization.

Table 1

Sample notations for different reaction conditions

\begin{tabular}{|c|c|c|c|c|c|c|c|c|}
\hline \multicolumn{3}{|c|}{$\begin{array}{l}\text { Cellulose:SP ratio }(\mathrm{w} / \mathrm{w}) \\
\text { at } 700 \mathrm{~W} \text { and } 75^{\circ} \mathrm{C}\end{array}$} & \multicolumn{3}{|c|}{$\begin{array}{l}\text { Microwave power (W) } \\
\text { at } 1: 3 \text { ratio and } 75^{\circ} \mathrm{C}\end{array}$} & \multicolumn{3}{|c|}{$\begin{array}{l}\text { Reaction temperature }\left({ }^{\circ} \mathrm{C}\right) \\
\text { at } 1: 3 \text { ratio and } 700 \mathrm{~W}\end{array}$} \\
\hline $1: 2$ & $1: 3$ & $1: 4$ & $400 \mathrm{~W}$ & $700 \mathrm{~W}$ & $1000 \mathrm{~W}$ & $35^{\circ} \mathrm{C}$ & $55^{\circ} \mathrm{C}$ & $75^{\circ} \mathrm{C}$ \\
\hline DAC-R1 & DAC-M & DAC-R3 & DAC-P1 & DAC-M & DAC-P3 & DAC-T1 & DAC-T3 & DAC-M \\
\hline
\end{tabular}




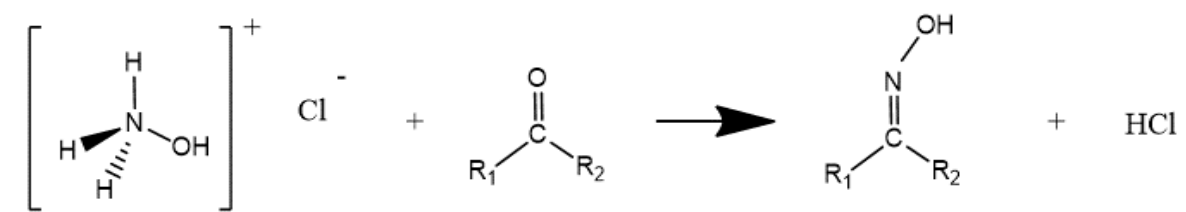

Scheme 1: Potential mechanism of oxime reaction used for aldehyde content analysis

\section{Aldehyde contents analysis}

Two methods were used to analyze the contents of aldehyde in DAC: FT-IR spectroscopy and titration. FT-IR analyses were performed to confirm the presence of aldehyde in DAC. FT-IR spectroscopy (Bruker, Vertex 70, USA), using the $\mathrm{KBr}$ method, was carried out in the range of $4000-500 \mathrm{~cm}^{-1}$ at $4 \mathrm{~cm}^{-1}$ resolution, with 64 scans. The titration method used a mixture of hydroxylamine hydrochloride and methyl orange to quantitatively estimate the content of aldehyde in DAC. ${ }^{20}$ During this process, a cellulose polyoxime [Cell- $(\mathrm{CH}=\mathrm{N}-\mathrm{OH})_{\mathrm{n}}$ ] was produced with $\mathrm{HCl}$ release equivalent for each formyl residue, as shown in Scheme $1 .^{20}$ The released $\mathrm{HCl}$ was titrated by an equivalent $0.1 \mathrm{~N} \mathrm{NaOH}$ solution, and the detailed procedure can be found in our previous work. ${ }^{11,20}$

The aldehyde content (AC\%) was calculated as follows:

AC $(\%)=\left[\left(\mathrm{M}_{\mathrm{NaOH}}\left(\mathrm{V}_{\text {sample }}-\mathrm{V}_{\text {control }}\right)\right) /\left(\mathrm{W}_{\mathrm{s}} / \mathrm{M}_{\text {glucose }}\right)\right] \mathrm{x} 100$

where $\mathrm{M}_{\mathrm{NaOH}}$ is the molecular weight of $\mathrm{NaOH}$ (40.00 $\mathrm{g} / \mathrm{mol}$ ), $\mathrm{V}_{\text {sample }}$ is the amount of $0.1 \mathrm{~N} \mathrm{NaOH}$ solution used for titration of DAC specimen $(\mathrm{L}), \mathrm{V}_{\text {control }}$ is the amount of $0.1 \mathrm{~N} \mathrm{NaOH}$ solution used for titration of pristine cellulose $(\mathrm{L}), \mathrm{W}_{\mathrm{s}}$ is the weight of the specimen used (0.1 g), and $\mathrm{M}_{\text {glucose }}$ is the molecular weight of the repeating unit $\left(\left(\mathrm{C}_{6} \mathrm{H}_{8} \mathrm{O}_{5}\right)_{\mathrm{n}}, 160.12 \mathrm{~g} / \mathrm{mol}\right)$ in the cellulose molecule.

\section{Water-solubility and particle size}

An amount of $0.1 \mathrm{~g}$ of sample ( $1 \mathrm{w} / \mathrm{w} \%)$ was added to $10 \mathrm{~mL}$ of deionized water to confirm the aqueous solubility of DAC nanoparticles. Their solubility was tested by stirring at room temperature for two hours, and then the undissolved specimens were further stirred at $55{ }^{\circ} \mathrm{C}$ for one hour. The particle size was measured by using the same specimens used in the solubility test. After diluting each sample to $0.03 \%, 1.5$ $\mathrm{mL}$ of the solution was prepared, and by the dynamic light scattering method (Zetasizer Nano ZS, Malvern, UK) the particle size was estimated, in three sets of 100 measurements at a fixed scattering angle of $173^{\circ}$. The average value of three sets was recorded.

\section{Other instrumental analyses}

The thermal behavior of DAC nanoparticles was investigated by employing a thermogravimetric analyzer (TGA/DSC1, Mettler, USA) in the temperature range of $25^{\circ} \mathrm{C}-800{ }^{\circ} \mathrm{C}$, at a heating rate of
$10{ }^{\circ} \mathrm{C} / \mathrm{min}$ under nitrogen atmosphere. X-ray diffraction (XRD, Bruker, D2 Phaser, USA) investigated changes in the crystalline structure of DAC. Analyses were carried out in the range of $2 \theta=10^{\circ}-40^{\circ}$ with a voltage of $30 \mathrm{kV}$, a current of 10 $\mathrm{mA}$, and $1 \% \mathrm{~min}$. Field emission scanning electron microscopy (FeSEM, Zeiss Ultra Plus, Germany) was used to determine the surface morphology changes of DAC caused by SP oxidation. The specimens were diluted to a $0.03 \%$ solution, dropped onto glass wafers, and dried in a convection oven. The dried specimens were evaluated at $15 \mathrm{KV}$ after platinum coating.

\section{RESULTS AND DISCUSSION FTIR analysis of aldehyde content}

FT-IR analysis confirmed the presence of dialdehyde introduced by the periodate oxidation of two secondary hydroxyl groups in the glucose ring, shown in Figure 1. Typical cellulose absorption peaks, such as the hydrogen-bonded $\mathrm{OH}$ stretching peak at $3300 \mathrm{~cm}^{-1}$, that at 3000 $2800 \mathrm{~cm}^{-1}$ corresponding to $\mathrm{sp}^{3}$ hybridized $-\mathrm{C}-\mathrm{H}$ stretching, the peak at $1640 \mathrm{~cm}^{-1}$ attributed to $\mathrm{OH}$ bending vibration of absorbed water, the peak at $1160 \mathrm{~cm}^{-1}$ ascribed to C-O-C asymmetry stretching inside the glucose ring, and that at 1060 $\mathrm{cm}^{-1}$ corresponding to C-O stretching vibrations, are clearly observed in the spectra. ${ }^{2,4,8,11}$ In addition, the newly appeared aldehyde carbonyl peak at $1730 \mathrm{~cm}^{-1}$ revealed that DAC was successfully formed by SP oxidation. As the peak at $1730 \mathrm{~cm}^{-1}$ increased, the hydroxyl group peak at $3300 \mathrm{~cm}^{-1}$ tended to decrease, but this decrease was not considerable due to the formation of hemiacetal between the introduced aldehyde groups and the water absorbed. The increase in the hemiacetal hydroxyl peak at $890 \mathrm{~cm}^{-1}$ also substantiated the hemiacetal formation. ${ }^{12}$ The peak intensity ratios were calculated by normalizing the aldehyde carbonyl peak at 1730 $\mathrm{cm}^{-1}$ by $1160 \mathrm{~cm}^{-1}$ for an asymmetric C-O-C peak within glucose to obtain accurate estimation of aldehyde groups. 


\section{DAC-M}

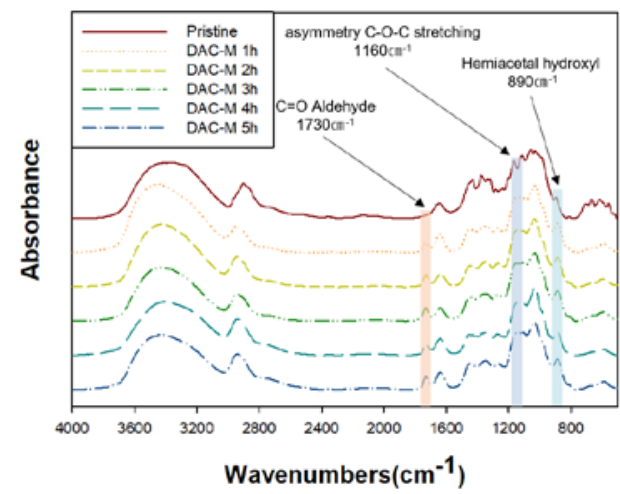

DAC-R1

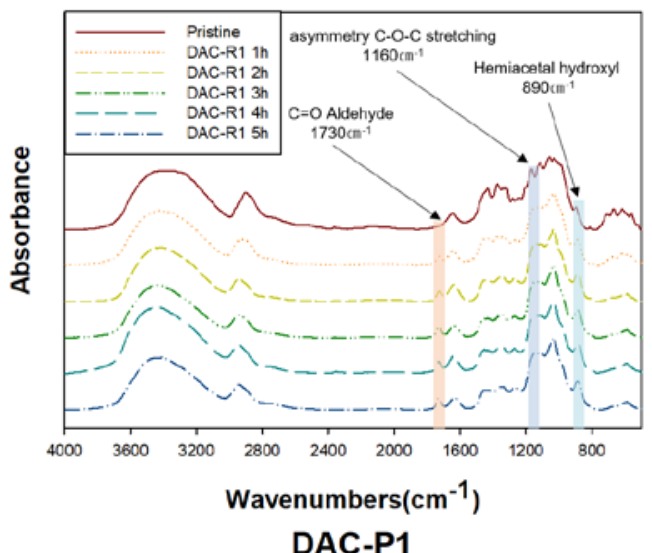

DAC-P1

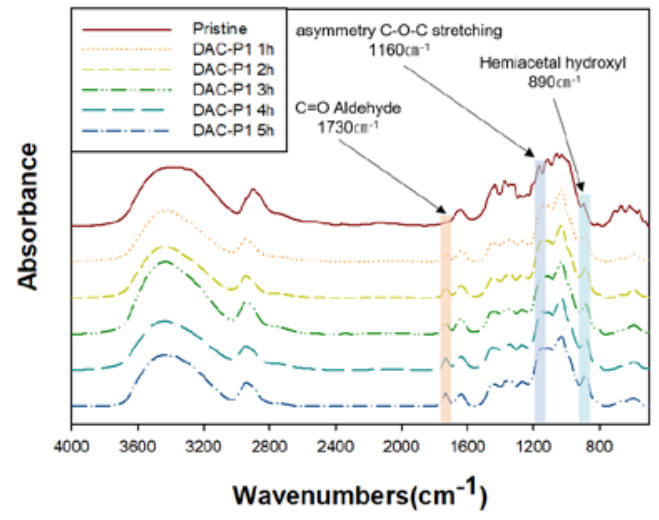

DAC-T1

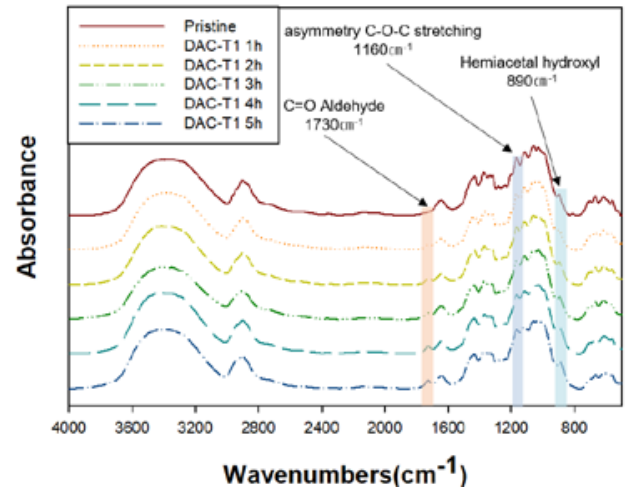

(a)

DAC-R3

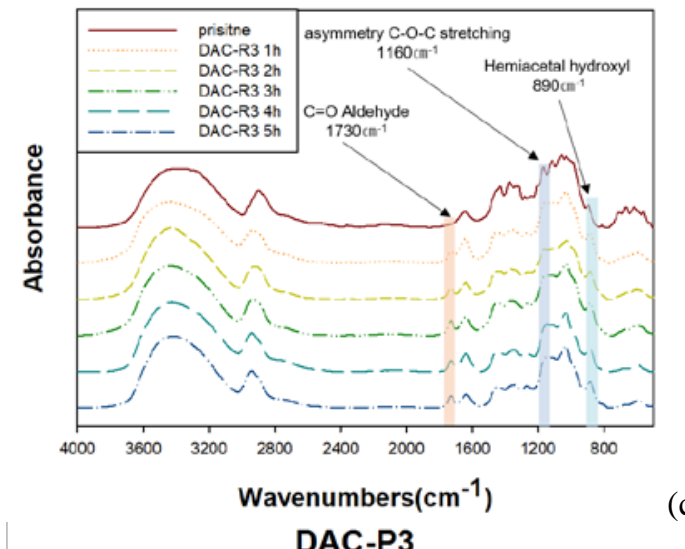

(c)

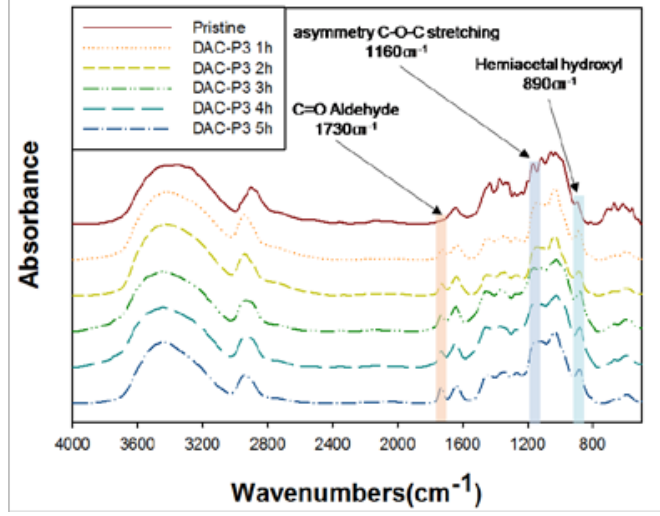

DAC-T3

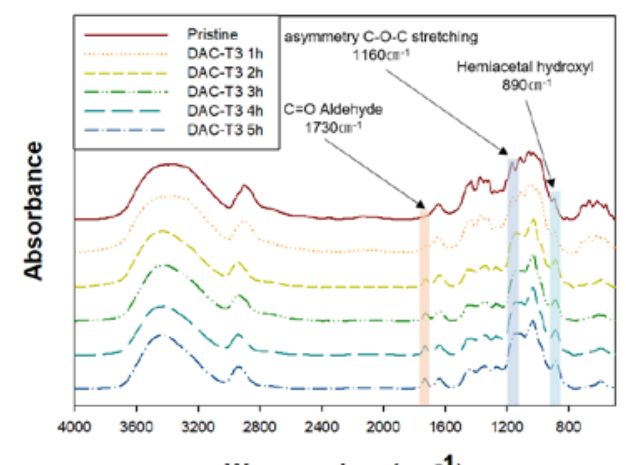

(g)

Figure 1: FT-IR spectra of DAC specimens; (a) DAC-M, (b) DAC-R1, (c) DAC-R3, (d) DAC-P1, (e) DAC-P3, (f) DAC-T1 and (g) DAC-T3 


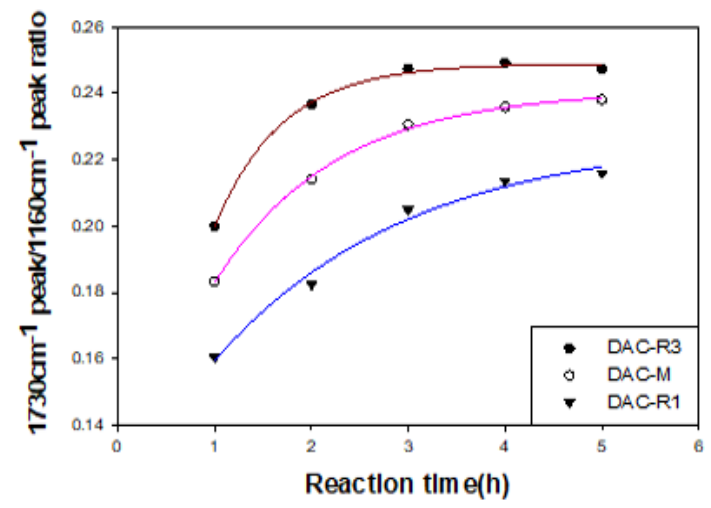

(a)

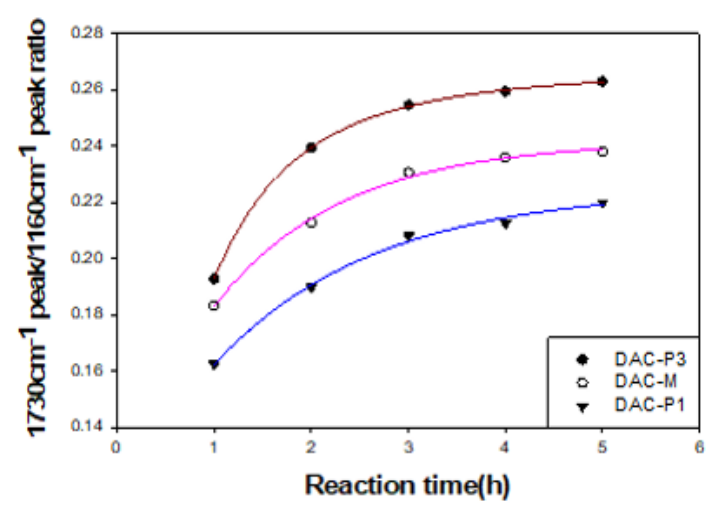

(b)

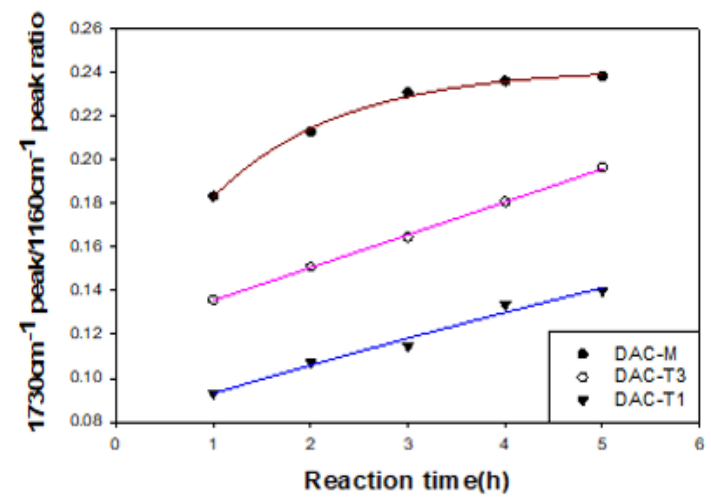

(c)

Figure 2: Peak intensity ratios (peak intensity of $1730 \mathrm{~cm}^{-1} / 1160 \mathrm{~cm}^{-1}$ ) in FTIR spectra; (a) DAC-R, (b) DAC-P, and (c) DAC-T

The results illustrated in Figure 2 demonstrate that these ratios increased with increasing SP concentration (cellulose to SP ratio), microwave radiation power and reaction temperature at a given irradiation time. In addition, the increases occurred at all the irradiation times. However, for a given experimental condition, the increase was more substantial with rising time at short irradiation times, i.e. from one to two hours, then tended to level off with further increase in irradiation time. The increase in the peak ratio with rising irradiation time and SP concentration has been also observed previously, ${ }^{12}$ but the time interval used in this study was much longer to ensure cellulose dissolution in water. This suggested that SP oxidation showed a two-step reaction rate: the initial step caused by a rapid oxidation of the amorphous state, followed by the second step - a slow rate of oxidation across the crystalline surface. In addition to the main oxidation reaction, the chain-cleavage of cellulose also occurred through hydrolytic scissions and $\beta$ alkoxy elimination at an extent that depended on the temperature, $\mathrm{pH}$, periodate concentration and time of reaction. ${ }^{2,9}$ These side reactions were attributed to the breaking of glycosidic bonds and reduction of the cellulose DP. ${ }^{2}$ Since the microwave irradiation provided high temperature SP oxidation, the chain-cleavage could be even greater, consequently, contributing to the formation of nanocellulose molecules and to their water solubility. It was also stated that high oxidation of the amorphous region and the chaincleavage accompanying oxidation produced nanocelluloses that were similar to those achieved by acid hydrolysis. ${ }^{2}$

\section{Aldehyde content analysis by titration}

Additional analysis by the titration method further provided quantitative estimation of aldehyde groups in DAC. ${ }^{20}$ This method also allowed visual observation by a methyl orange indicator. In order to verify the effects of various reaction conditions, the ACs (\%) were plotted as a function of the SP ratio, microwave power and reaction temperature in Figure 3. These results corroborated that the increase in AC (\%) gradually diminished after the initial rapid increase in AC (\%) between one and two hours of reaction time, and this trend is in agreement with 
the results obtained by FT-IR analysis. This was also validated in Figure 4, where all the data were plotted at once for different conditions. Almost all the samples reached a plateau near $89 \%$ of AC (\%), except when using $1000 \mathrm{~W}$ of microwave power. Since the ACs (\%) of DAC-P3 were around $96 \%$ for both 4 and 5 hours of reaction time, this suggested the importance of microwave power for dialdehyde formation. Furthermore, unlike other conditions, the specimens with low reaction temperatures, such as DAC-T1 at $35{ }^{\circ} \mathrm{C}$ and DAC-T3 at $55{ }^{\circ} \mathrm{C}$, resulted in very low AC (\%), along with its linear increase, suggesting the

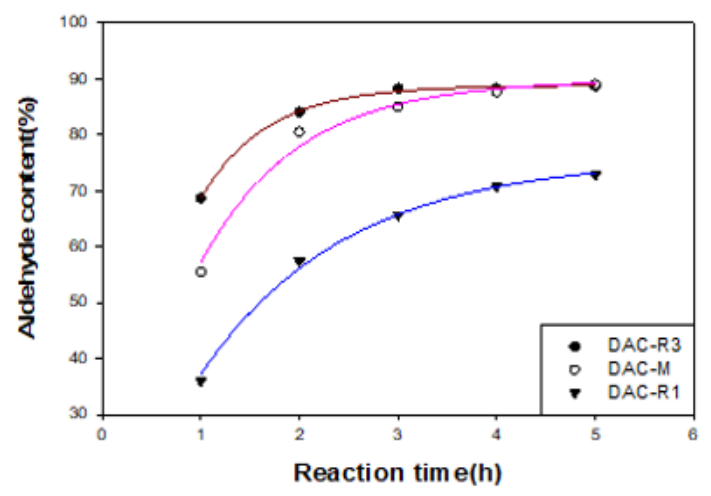

(a) presence of insufficient SP oxidation in the amorphous regions at these temperatures.

Moreover, as shown in Figure 4, the AC (\%) of DAC-R3 was initially greater than that of DACP3, as $68.67 \%$ versus $59.51 \%$, respectively, but the AC (\%) of two specimens became opposite at much longer irradiation, as $88.69 \%$ versus $96.80 \%$ at five hours. Thus, we suggest that the SP concentration was more important in the initial stage of oxidation in the amorphous region, but later the microwave power became a more critical factor in affecting the oxidation reaction in the crystalline region.

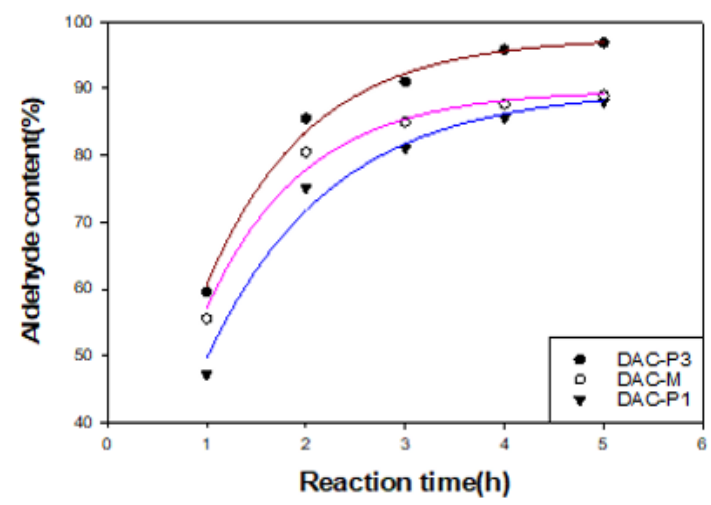

(b)

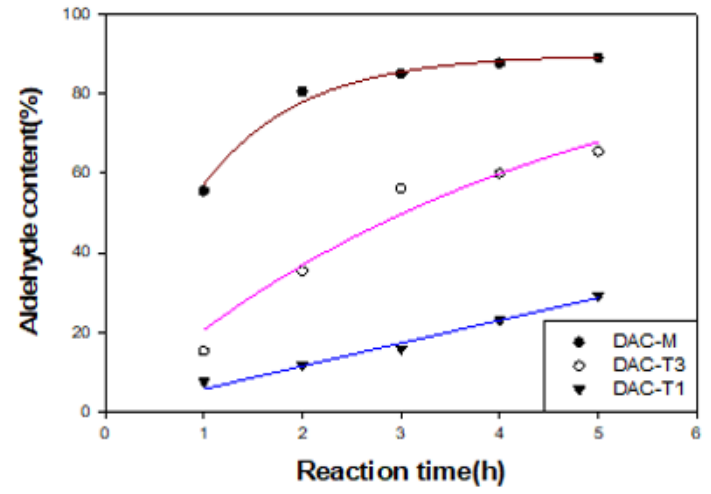

(c)

Figure 3: Percent aldehyde content analysis by titration; (a) DAC-R, (b) DAC-P and (c) DAC-T

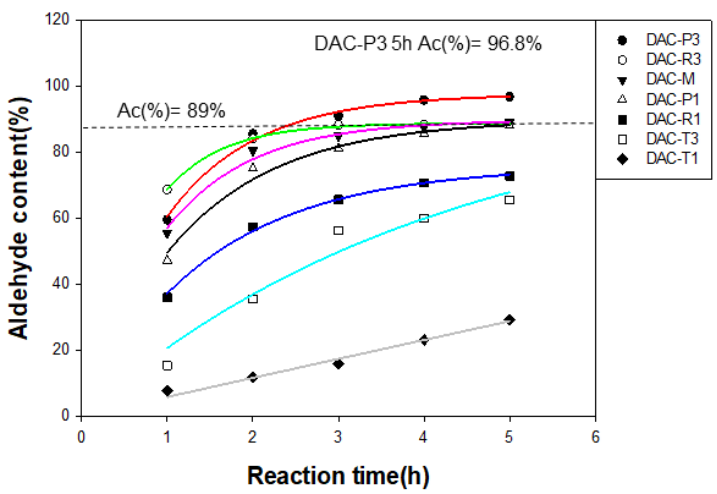

Figure 4: Percent aldehyde contents at various experimental conditions. 


\section{Water solubility and particle size of DAC}

The DAC specimens produced under various reaction conditions were placed in distilled water to examine their water solubility. ${ }^{1,4}$ Five specimens, namely DAC-M 4h, DAC-M 5h, DAC-R3 4h, DAC-R3 5h and DAC-P3 4h, readily dissolved in water by a simple stirring at room temperature (Fig. 5). On the other hand, three specimens, namely DAC-P1 5h, DAC-P3 $3 \mathrm{~h}$ and DAC-P3 5h, dissolved in water only after an additional heating at $55^{\circ} \mathrm{C}$ for one hour. Since the first two specimens with low solubility had smaller z-averages (smaller particles), as shown in Table 2, no direct relationship was found between particle size and water solubility. Two factors could contribute to the water solubility of DAC nanoparticles: firstly, the introduction of hydrophilic dialdehyde groups and secondly, chain-cleavage occurred by the hydrolytic scissions and $\beta$-alkoxy elimination accompanying the oxidation reaction. Since the DAC specimen with the highest AC (\%), of 96.8\%, dissolved in water only upon additional heating, there must be other factors that determined their water solubility. The low water solubility of DAC with 96.8\% AC can be attributed to the formation of stable, covalent hemiacetal linkages, as shown in
Figure 1, between the created aldehyde groups and adjacent hydroxyl groups. ${ }^{9}$ In addition, perfect crystallization of the DAC surface by extremely high contents of dialdehyde and oxidation could also reduce water solubility, because of the removal of all the amorphous regions. ${ }^{23}$

Particle size was evaluated for the eight specimens tested for their water solubility, and the results are shown in Figure 6 and Table 2. Figure 6 (a) and (b) shows representative chromatograms for DAC-M 4h and DAC-P3 5h, respectively. The results confirmed that the highest intensity peak of each sample (Peak 1 mean) was indicative of particles of 200-300 nm sizes for all the specimens. These particle sizes were pretty much similar to the crystallite sizes of nanocrystalline celluloses reported in previous studies. ${ }^{8,9}$ In addition, the particles of several $\mathrm{nm}$ were presumed to be amorphous residues, which had not degraded yet, and the particles of over a thousand $\mathrm{nm}$ were degrading microfibrils. ${ }^{8}$ In DAC-P3 5h, with the highest AC (\%) of 96.8\%, the peak representing particles of several $\mathrm{nm}$ disappeared, as seen in Figure 6 (b), suggesting complete removal of the amorphous material.

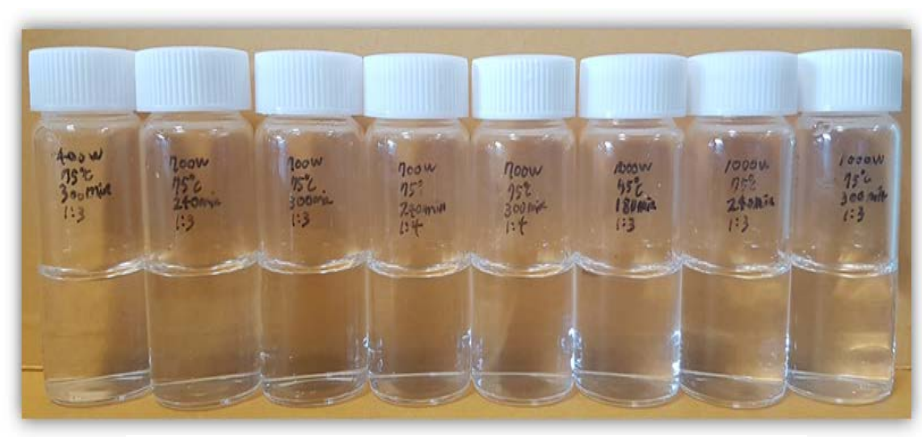

Figure 5: Water-solubility of DAC nanoparticles.

Table 2

Particle size of various specimens

\begin{tabular}{lccc}
\hline $\begin{array}{l}\text { Specimen with } \\
\text { microwave time }(\mathrm{h})\end{array}$ & $\begin{array}{c}\text { z-average } \\
(\mathrm{d}, \mathrm{nm})\end{array}$ & $\begin{array}{c}\text { Peak 1 mean size } \\
(\mathrm{d}, \mathrm{nm})\end{array}$ & $\begin{array}{c}\text { Peak 1 area integration } \\
(\%)\end{array}$ \\
\hline DAC-M 4h & 235.9 & 272.0 & 86.0 \\
DAC-M 5h & 181.5 & 261.8 & 66.9 \\
DAC-R3 4h & 268.8 & 289.2 & 88.8 \\
DAC-R3 5h & 259.5 & 282.5 & 84.3 \\
DAC-P1 5h & 197.2 & 283.0 & 79.8 \\
DAC-P3 3h & 147.8 & 216.8 & 86.9 \\
DAC-P3 4h & 157.7 & 236.6 & 76.0 \\
DAC-P3 5h & 228.8 & 278.8 & 90.6 \\
\hline
\end{tabular}




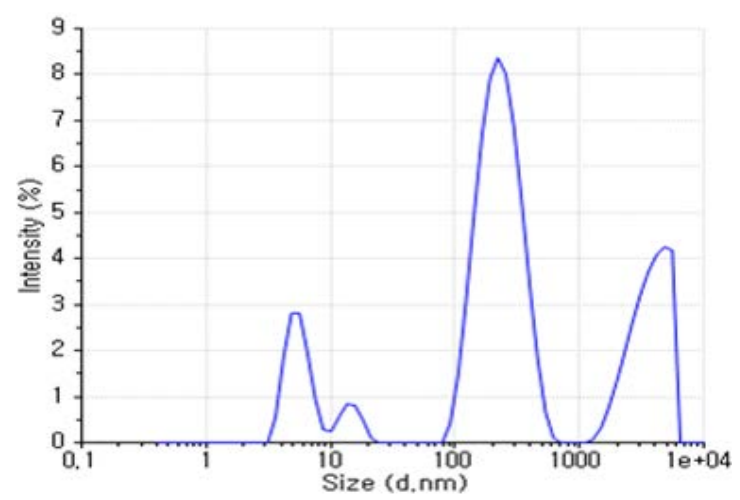

(a)

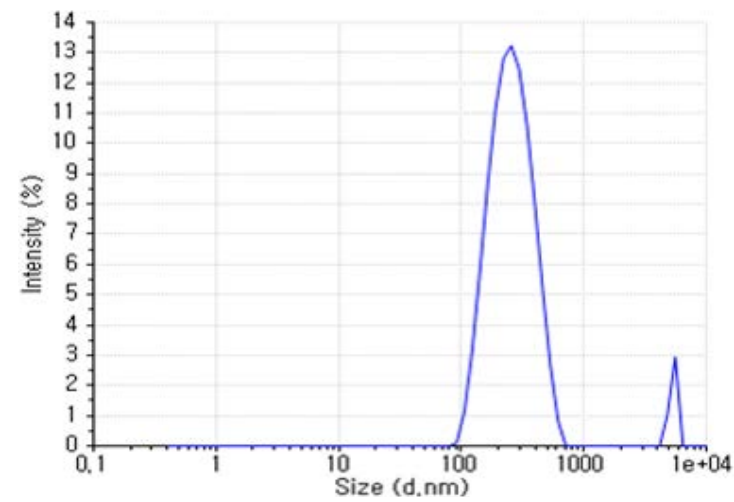

(b)

Figure 6: Particle size distribution chart, (a) DAC-M 4h and (b) DAC-P3 5 h

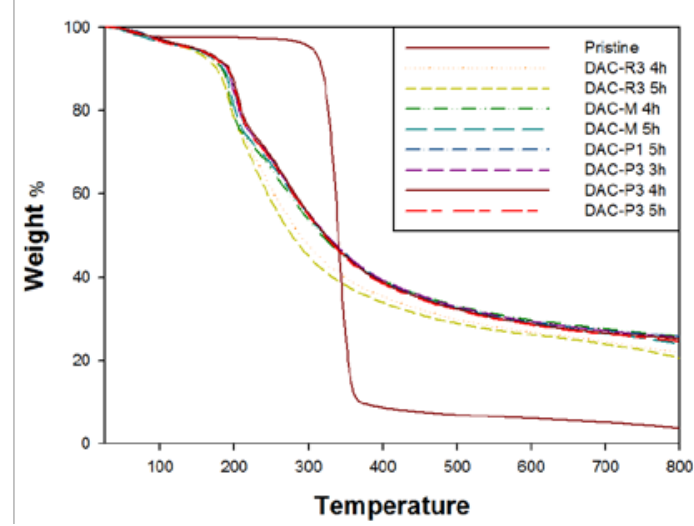

(a)

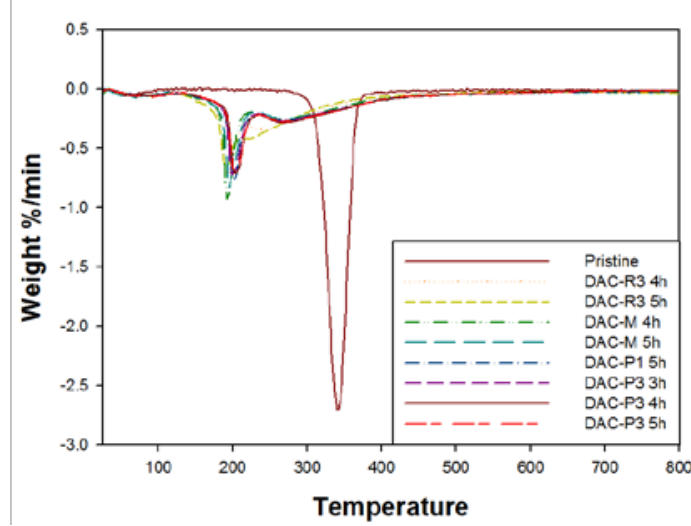

(b)

Figure 7: Thermogravimetric analysis of pristine cellulose and various DAC specimens, (a) TGA curves and (b) $1^{\text {st }}$ derivative curves

\section{Thermal behavior analysis}

The thermogravimetric analyzer (TGA) investigated the thermal behavior of various specimens, as shown in Figure 7. Pristine cellulose showed thermal decomposition around $350{ }^{\circ} \mathrm{C}$, while DAC had a wide decomposition range between $200{ }^{\circ} \mathrm{C}$ and $350{ }^{\circ} \mathrm{C}$. This was due to damage of natural crystalline and amorphous phases of cellulose produced by the chaincleavage accompanying SP oxidation. Unlike pristine cellulose, DAC showed relatively high residue, which was thought to be due to the crosslinking that occurred by acetal formation derived from the reaction between aldehyde and the hydroxyl groups within the oxidized cellulose. ${ }^{21}$ This was substantiated by the increase in the hemiacetal peaks revealed by FTIR analyses (Fig. 1), with the increase in microwave irradiation times.

\section{$\mathrm{X}$-ray diffraction analysis}

The crystal structure changes of DAC upon SP oxidation were analyzed by XRD, as shown in Figure 8. Characteristic cellulose $\mathrm{I}_{\beta}$ crystalline peaks at $2 \theta$ of $14.7^{\circ}, 16.8^{\circ}$ and $22.7^{\circ}$, which correspond to the reflections (1-10), (110) and (020), respectively, were observed. ${ }^{24}$ The results indicated that the crystalline peak at $2 \theta$ of $22.7^{\circ}$ continuously decreased with the progress of SP oxidation. It was found that the peaks of (020) planes decreased in almost all the samples, which completely disappeared at $56.3 \%$ or more AC (\%), and this result was substantiated by previous studies. ${ }^{8,22}$ 


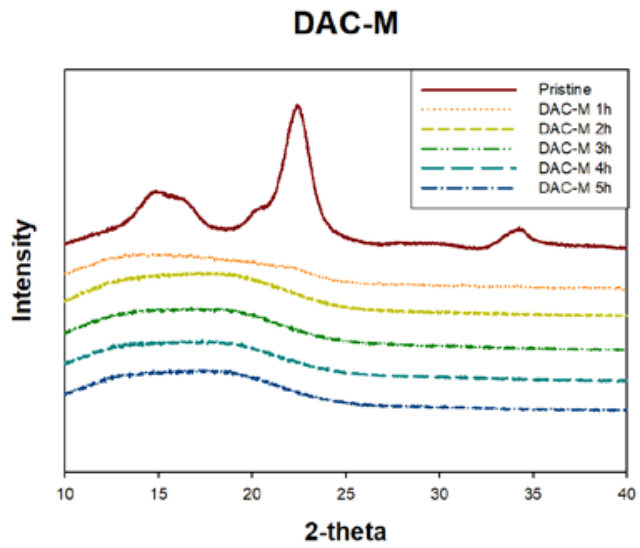

DAC-R1

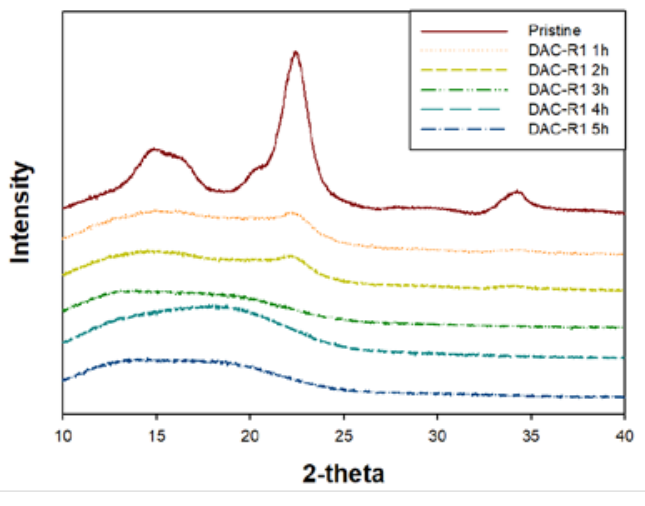

DAC-P1

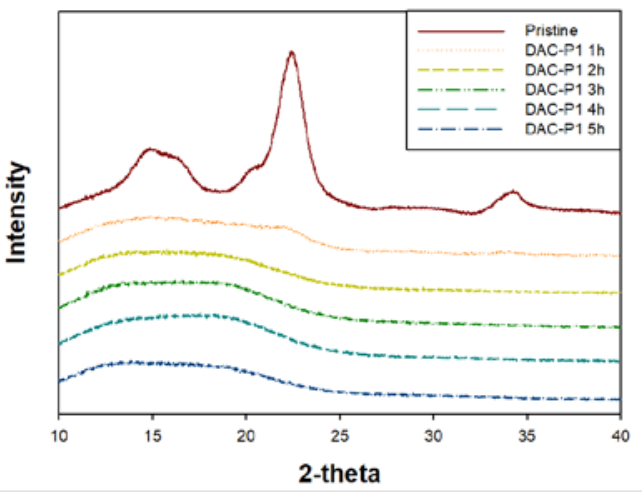

DAC-T1

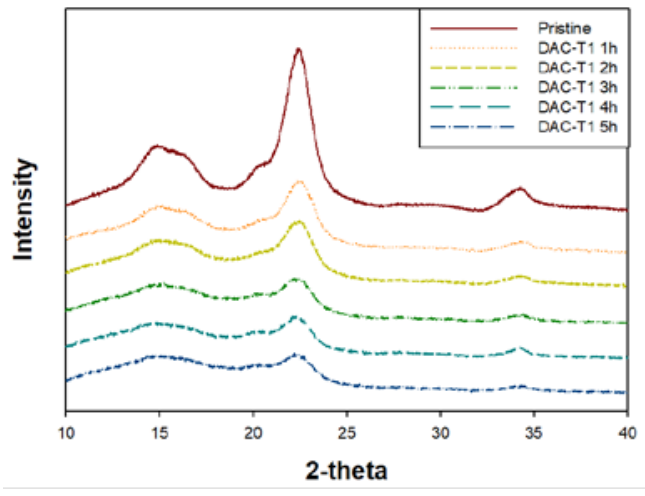

(b)

(d)

(f) (a)

DAC-R3
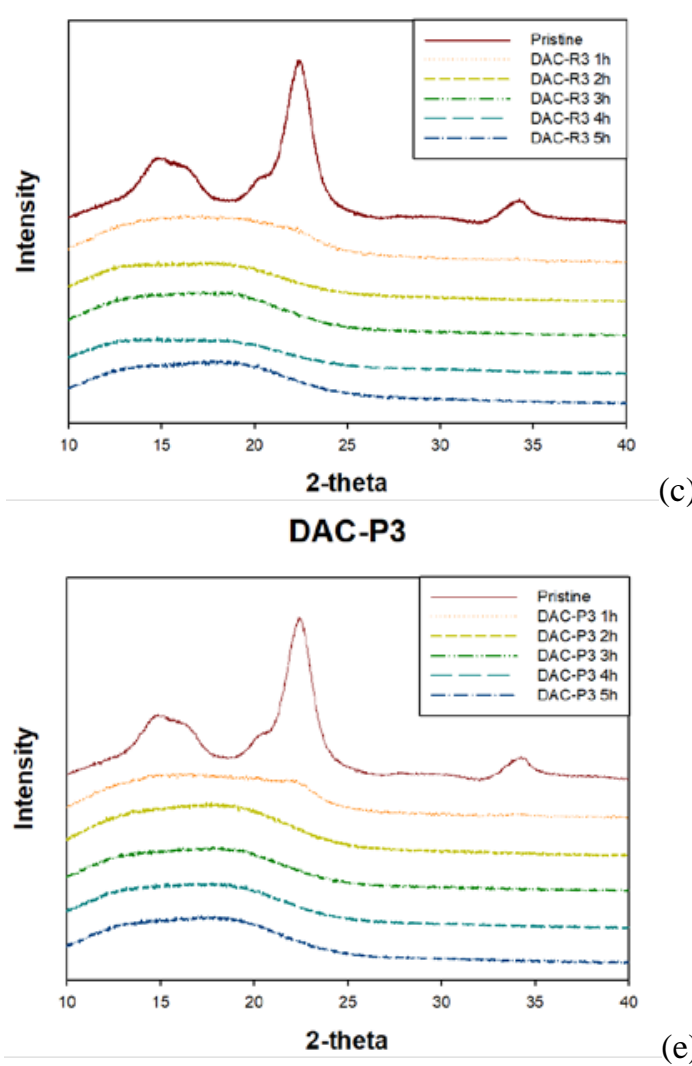

(e)

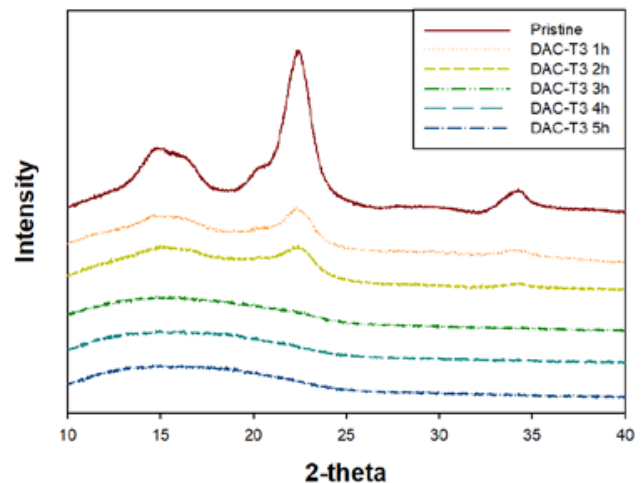

(g)

Figure 8: X-ray diffraction patterns for various DAC specimens; (a) DAC-M, (b) DAC-R1, (c) DAC-R3, (d) DAC-P1, (e) DAC-P3, (f) DAC-T1 and (g) DAC-T3 


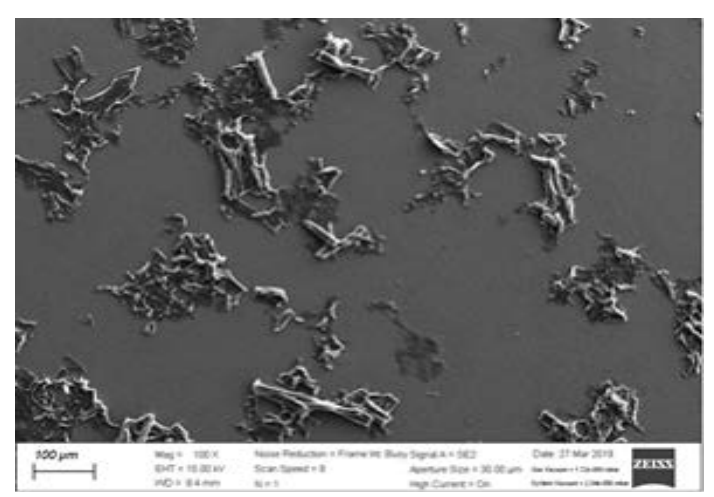

(a)

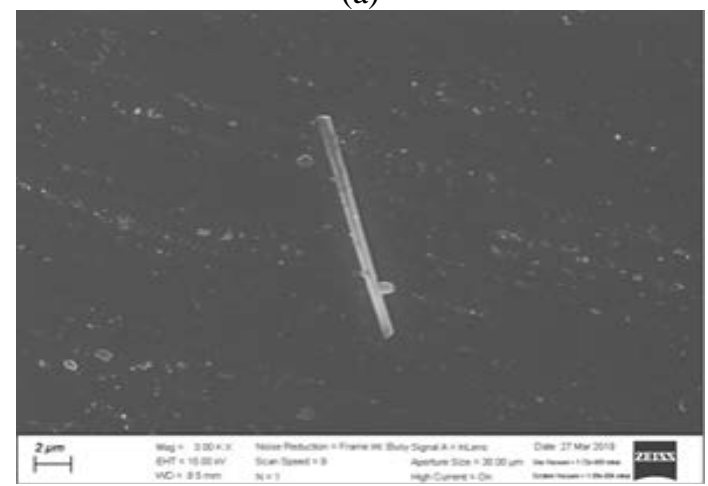

(c)

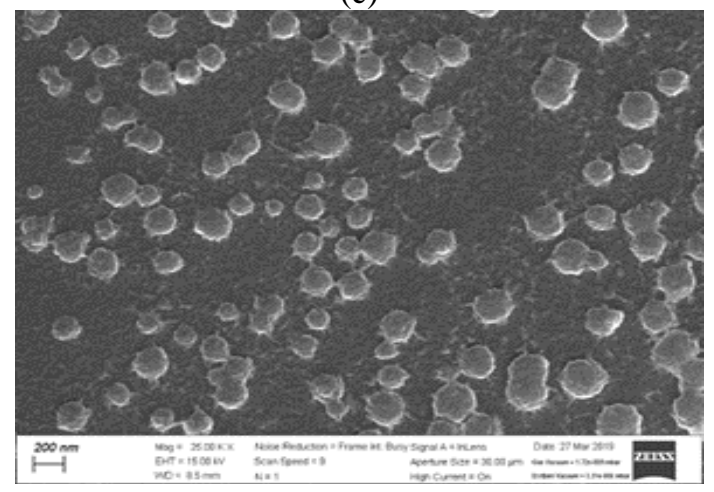

(e)

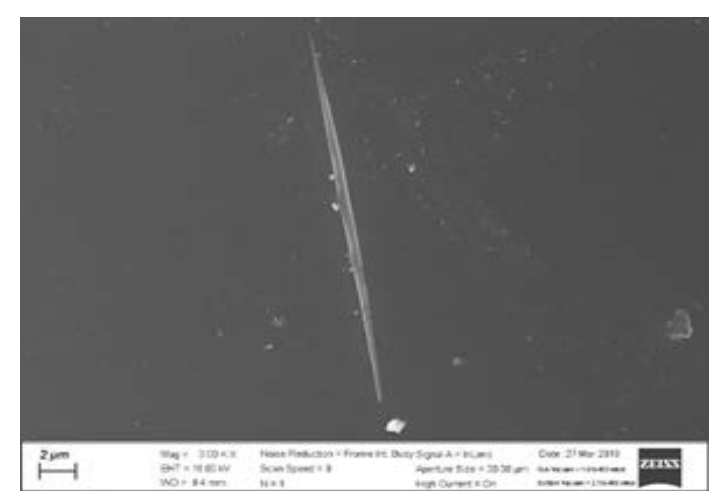

(b)

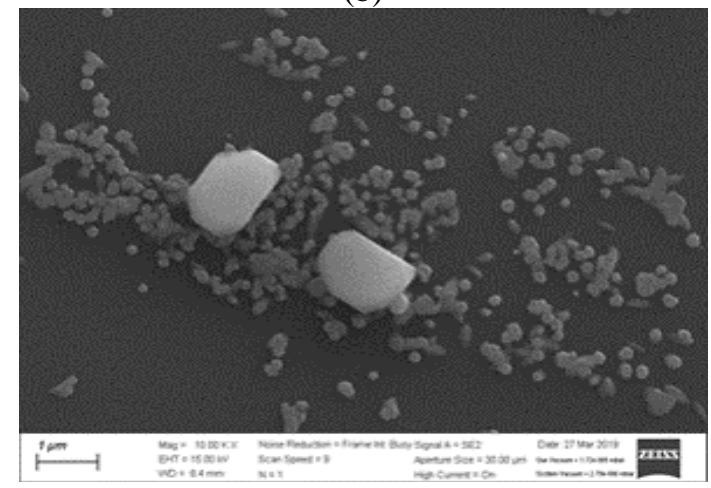

(d)

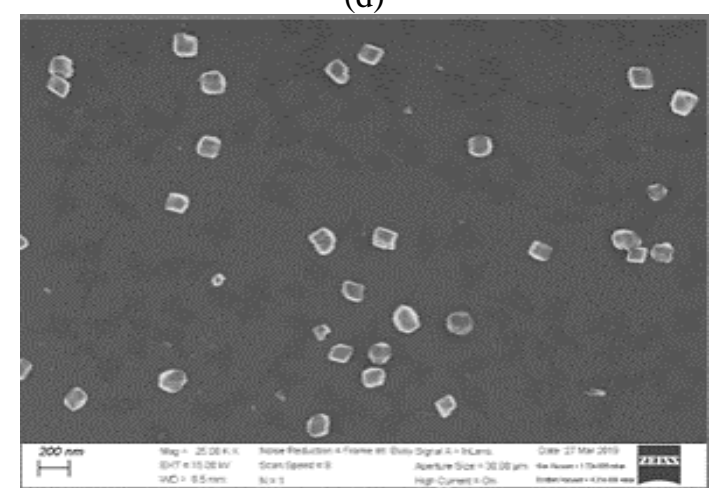

(f)

Figure 9: FeSEM micrographs; (a) DAC-M 1h, (b) DAC-M 2h, (c) DAC-M 3h, (d) DAC-M 4h, (e) DAC-M 5h, and (f) DAC-P3 $5 h$

The decrease of the crystalline peak upon SP oxidation was caused by breakage of the crystalline structure by weakening packing capacity and intra- or inter-molecular hydrogen bonding upon cleavage of the C2-C3 carbon bond and, consequently, replacement of C2-C3 hydroxyl groups by dialdehyde groups. ${ }^{21,22}$ This was again confirmed by the increase in the amounts of aldehyde groups by both FT-IR and aldehyde contents analyses. Furthermore, DACT1 and DAC-T3 specimens, which had not yet sufficiently oxidized, showed small crystalline peaks of the (020) plane, as seen in Figure 8 (f) and (g), respectively.

\section{DAC nanoparticle morphology analysis}

FeSEM analysis confirmed morphology changes occurring in DAC specimens as the SP oxidation progressed. Therefore, five DAC-M specimens, prepared with one to five hours of microwave irradiation, and the DAC-P3 5h specimen, with the highest AC (\%), were analyzed. In the micrograph of DAC-M $1 \mathrm{~h}$ in Figure 9 (a), the cellulose particles are noted to be quite large and irregular in shape, they tended to coagulate together, suggesting that cellulose nanoparticles were not sufficiently produced. In the specimens produced with two and three hours of microwave irradiation, the fibrils were either 
peeled off (Fig. 9 (b)) or split in the longitudinal direction (Fig. 9 (c)). On the other hand, in the specimens produced with four hours or longer microwave irradiation, cellulose nanoparticles were formed, as shown in Figure 9 (d), (e) and (f). Especially in the case of the specimens prepared with five-hour irradiation (Fig. 9 (e) and (f)), the nanoparticles were uniform and smaller, with sizes from $200 \mathrm{~nm}$ to $300 \mathrm{~nm}$, as previously confirmed by the DLS study. These results indicated that the cellulose nanoparticles were well formed with microwave irradiation of four hours or longer, when a high level of dialdehyde was produced, along with chain cleavage, accompanying oxidation. This result is also in agreement with the findings of a previous study. ${ }^{2}$

\section{CONCLUSION}

This study aimed to produce water-soluble dialdehyde nanocellulose under microwave irradiation. Microwave irradiation considerably increased the collision of SP molecules by their direct heating, rather than in conventional heating, consequently, reducing the process duration for preparing water-soluble cellulose nanoparticles. FT-IR analysis revealed an increase in the aldehyde carbonyl peak observed at $1730 \mathrm{~cm}^{-1}$, indicating successful formation of DAC by periodate oxidation. In addition, the peak ratios of the aldehyde carbonyl and asymmetric C-O-C peaks also increased with an increase in SP concentration, microwave radiation power and reaction temperature at a given irradiation time. The results achieved by FT-IR and AC (\%) analyses indicated the presence of two oxidation rates, with a rapid initial step in the amorphous region, followed by a slower second step on the crystalline surface.

The five samples prepared under four hours or longer microwave irradiation were dissolved in water by simple stirring at room temperature. Three other specimens were solubilized only after additional heating at $55{ }^{\circ} \mathrm{C}$ for one hour. DLS analysis showed that the major particle size portion of the soluble DAC was around 200-300 $\mathrm{nm}$, which is indicative of nanocrystalline cellulose. In particular, the particles of a few $\mathrm{nm}$ disappeared in the case of DAC-P3 5h, i.e. the specimen with the highest AC (\%), suggesting the complete decomposition of the amorphous region. The TGA analysis confirmed a decrease of thermal stability caused by the chain cleavage in DAC molecules upon SP oxidation and an increase in the content of residue owing to the crosslinking upon hemiacetal formation. XRD analysis substantiated the decrease in the crystalline structures due to ring breakage causing the decrease in hydrogen bonding and packing capacity. FeSEM analyses verified some morphological changes in the oxidized cellulose, indicating the formation of uniform cellulose nanoparticles under four hours or longer microwave irradiation.

Heating with microwave irradiation during SP oxidation enabled the production of water-soluble dialdehyde nanocellulose. The study confirmed that the microwave radiation power could substantially affect the rate of SP oxidation, and this was also found to have a greater effect in the crystalline region than in the amorphous one.

\section{REFERENCES}

1 L. Münster, J. Vícha, J. Klofáč, M. Masař, A. Hurajová et al., Carbohyd. Polym., 198, 181 (2018), https://doi.org/10.1016/j.carbpol.2018.06.035

2 A. Errokh, A. Magnin, J. Putaux and S. Boufi, Cellulose, 25, 3899 (2018), https://doi.org/10.1007/s10570-018-1871-7

3 C. Kim, D. Kim, S. Kang, M. Marquez and Y. Joo, Polymer, 47, $5097 \quad$ (2006), https://doi.org/10.1016/j.polymer.2006.05.033

4 U. Kim, M. Wada and S. Kuga, Carbohyd. Polym., 56 , 7 (2004),

https://doi.org/10.1016/j.carbpol.2003.10.013

J. Zhao, W. Zhang, X. Zhang, X. Zhang, C. Lu et al., Carbohyd. Polym., 97, 695 (2013), https://doi.org/10.1016/j.carbpol.2013.05.050

6 L. Zhang, T. Tsuzuki and X. Wang, Cellulose, 22, 1729 (2015), https://doi.org/10.1007/s10570-015-0582$\frac{6}{7}$

7 A. Isogai, T. Saito and H. Fukuzumi, Royal Soc. Chem., 3, 71 (2011), https://doi.org/10.1039/C0NR00583E

${ }^{8}$ U. Kim, S. Kuga, M. Wada, T. Okano and T. Kondo, Biomacromolecules, 1, 488 (2000), https://doi.org/10.1021/bm0000337

9 A. Potthast, M. Kostic, S. Schiehser, P. Kosma and T. Rosenau, Holzforschung, 61, 662 (2007), https://doi.org/10.1515/HF.2007.099

10 X. Tian and X. Jiang, Cellulose, 25, 987 (2018), https://doi.org/10.1007/s10570-017-1607-0

11 S. Park and H. Choi, Cellulose Chem. Technol., 52, 311

(2018),

https://www.cellulosechemtechnol.ro/pdf/CCT52, 34(2018)/p.311-322.pdf

12 J. H. Park, H. Choi and K. Oh, Cellulose, 21, 3107 (2014), https://doi.org/10.1007/s10570-014-0326-z

13 T. H. S. Maia, N. M. Larocca, C. Beatrice, G. Siqueira, L. A. Pessan et al., Carbohyd. Polym., 173, 50

(2017), 
https://doi.org/10.1016/j.carbpol.2017.05.089

14 J. Sirvio, U. Hyvakko, H. Liimatainen, J. Niinimaki and O. Hormi, Carbohyd. Polym., 83, 1293 (2011), https://doi.org/10.1016/j.carbpol.2011.04.054

15 A. J. Varma and M. P. Kulkarni, Polym. Degrad. Stabil., 77, 25 (2002), https://doi.org/10.1016/S01413910(02)00073-3

16 J. Sirviö, H. Liimatainen, J. Niinimäki and O. Hormi, Carbohyd. Polym., 86, 260 (2011), https://doi.org/10.1016/j.carbpol.2011.04.054

17 C. Ruan, M. Strømme and J. Lindh, Carbohyd. Polym., 181, 200

(2018),

https://doi.org/10.1016/j.carbpol.2017.10.072

18 A. Hoz, Á. Díaz-Ortiz and A. Moreno, Chem. Soc. Rev., 34, 164 (2005), https://doi.org/10.1039/B411438H

19 P. Lidstrom, J. Tierney, B. Wathey and J. Westman, Tetrahedron, 57, $9225 \quad$ (2001), https://doi.org/10.1016/S0040-4020(01)01071-7
20 H. Zhao and N. D. Heindel, Pharmaceut. Res., 8, 400 (1991), https://doi.org/10.1023/A:1015866104055

21 U. Kim and S. Kuga, Thermochim. Acta, 369, 79 (2001), https://doi.org/10.1016/S0040-6031(00)00734$\frac{6}{22}$

S. Park, J. O. Baker, M. E. Himmel, P. A. Parilla and D. K. Johnson, Biotechnol. Biofuel., 24, 3 (2010), https://doi.org/10.1186/1754-6834-3-10

23 V. B. Chavan, B. D. Sarwade and A. J. Varma, Carbohyd. Polym., 50, $41 \quad$ (2002), https://doi.org/10.1016/S0144-8617(01)00367-8

24 A. D. French, Cellulose, 21, 885 (2014), https://doi.org/10.1007/s10570-013-0030-4

25 D. Perez, S. Montanari and M. R. Vignon, Biomacromolecules, 4, 1417 (2003), https://doi.org/10.1021/bm034144s 